\title{
What Makes Ms. Johnson Teach? A Study of Teacher Motivation
}

\author{
Ronald D. Sylvia ${ }^{1}$ and Tony Hutchison \\ University of Oklahoma
}

The need configurations underlying the motivations of public school teachers are examined here with regard to teacher perceptions of pay equity relative to other factors such as work autonomy, intrinsic work elements, and satisfaction of so-called higher-order needs. A $Q$ sort forced distributions research instrument containing 37 attitudinal statements was administered to a group of 167 teachers of a medium-sized city in Oklahoma. The survey netted 135 usable questionnaires (76\%). The data were $\mathrm{R}$ factor analyzed producing six clear factors, which dealt with: social variables and collegial support; positive supervisor relations; gratification from intrinsic work elements and dissatisfaction with extrinsic elements such as pay and benefits; interesting work and appropriate responsibility levels; opportunities for learning and development combined with negative attitudes about day-to-day duties; and job security, clear expectations, and excessive workloads. The study concluded that teacher motivation is based in the freedom to try new ideas, achievement of appropriate responsibility levels, and intrinsic work elements. The latter were of transcendent importance to our respondents. Based upon our findings, schemes such as merit pay were predicted to be counterproductive in service organizations which employ professionally trained people.

\section{INTRODUCTION}

The popular press recently has focused upon the issue of merit pay for teachers as a partial solution to the problems of American education. The assumptions of merit pay are rooted in the ideology of a market

\footnotetext{
'Requests for reprints should be sent to Ronald D. Sylvia, Department of Political Science,
} 455 West Lindsey Street, Room 205, University of Oklahoma, Norman, OK 73019. 
economy which may not be wholesaleably transferable to public organizations whose rank and file employees are professionally trained.

The importance of the controversy, however, goes beyond its impacts upon public schools. Merit pay for highly autonomous professional workers, such as teachers, also has relevance for management theory regarding motivation. The literature on the ability of pay to motivate is mixed. Some theories seek to understand the basic configuration of human needs as they relate to the workplace. Maslow (1954) and Herzberg (1966), for example, believe that people have higher- and lower-order needs. For Maslow, gratification of lower needs, such as security, pay, etc. leads to the emergence of higher-order needs involving social relations, esteem, and actualization. Gratification of these higher-order needs is believed necessary for true job satisfaction. For Herzberg, higher and lower needs operate independently. Gratification of lower-order needs is essential to employee retention but cannot lead to satisfaction/motivation. Satisfaction can only come from the gratification of higher-order needs. For both Maslow and Herzberg, pay is a lower-order need and, as such, cannot lead to true gratification.

The most widely tested theory of motivation through rewards is known variously as path-goal theory (Georgopoulous, 1957), instrumentality theory (Vroom, 1964), and expectancy valence theory (Porter \& Lawler, 1968). Research on the theory initially sought to determine the relationship between pay and motivation. The theory postulated that rewards would lead to performance insofar as the reward was viewed as leading to a desired secondary outcome. Empirical tests of the theory, however, demonstrated that the motivation to work is a highly complex process in which the effort level expended by an individual is a function of the forces to expand specific levels of effort, the expectation that a given level of effort will or will not accomplish the task, the valence of the goal accomplishments/failure for job outcomes, the relevance of the job outcomes, the perceived instrumentality of job outcomes for need gratification, and the valence of the basic need(s) of the individual in question (Campbell \& Pritchard, 1976).

Given the foregoing lack of consensus on pay as a motivator, it seems worthwhile to explore the perceptions of public school teachers regarding their profession before undertaking broad-based incentive programs. The research sought to address the following broad research questions:

What sorts of need configurations underly the motivation of teachers? To what degree are teachers satisfied/dissatisfied with current pay levels? And, how important is pay relative to other factors such as work autonomy, intrinsic work elements, responsibility levels, and the satisfaction of so-called higher-order needs? 


\section{THE STUDY}

Subjects. The subjects were the teachers and professional staff of a medium-sized city in western Oklahoma. As expected, the respondents were predominantly female $(76 \%)$. In addition, some respondents divided their time between teaching and other activities such as counseling and coaching. Data collection took place during a staff workshop. A total of 167 questionnaires were distributed and completed in a group while the researcher waited. A total of 135 usable questionnaires were returned for a return rate of $81 \%$.

Methodology. The study utilized the $\mathrm{Q}$ sort forced distribution technique (Stephenson, 1953; Brown, 1980). The forced distribution asks subjects to sort job attitudinal statements using a +3 through 0 to a -3 scale. Subjects are limited as to the number of statements to which they may yield a strong positive or negative response. In the current study, respondents were limited to three extreme and four somewhat extreme responses at each end of the scale. Q sorting avoids the halo effect sometimes encountered when using standard attitudinal questionnaires in which respondents need not weigh the importance of one response against another. Subjects were also asked to write a paragraph or two in which they explained their reasons for grouping their extreme responses as they did.

Instrument. Each subject received a Q sort containing 37 attitudinal statements which represent a ten-factor design of the elements which the literature has found relevant to work motivation and satisfaction. The factors are: (1) authority/autonomy, (2) social factors, (3) organization work expectations, (4) intrinsic work elements, (5) opportunity for selfdevelopment, (6) rewards/benefits, (7) recognition/esteem, (8) supervisor relations, (9) opportunity for community service, and (10) general overall satisfaction.

In order to put the data in perspective, the means and standard deviations were calculated for each of the 37 questionnaire items. These data are reported in Table I. The data are arranged on the basis of the descending order of their mean values.

The three statements which were most positively received by the respondents were as follows: Item 18, "My work is important and gives me a feeling of accomplishment"; Item 19, "My work is a benefit to the community"; and Item 7, "The people I work with are friendly." This premier item dealt with gratification from important work. The work character statement is reinforced further by the fourth through sixth strongest items which cover interesting work, the performance of day-to-day activities and overall job satisfaction. 


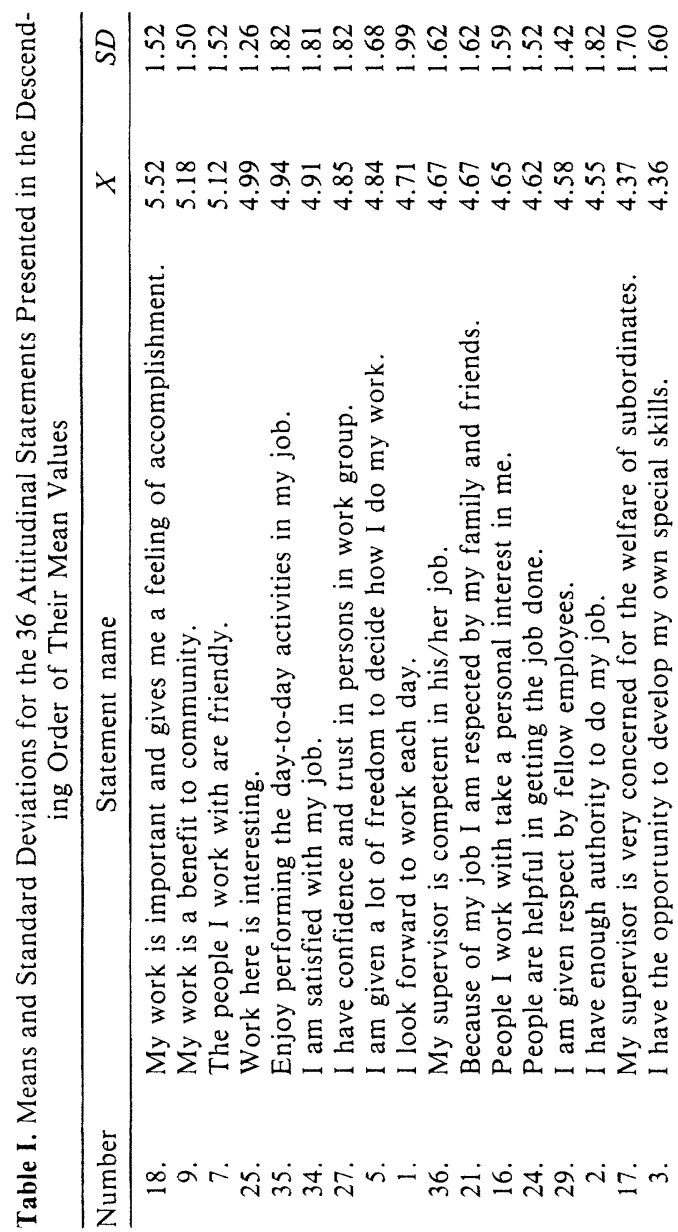




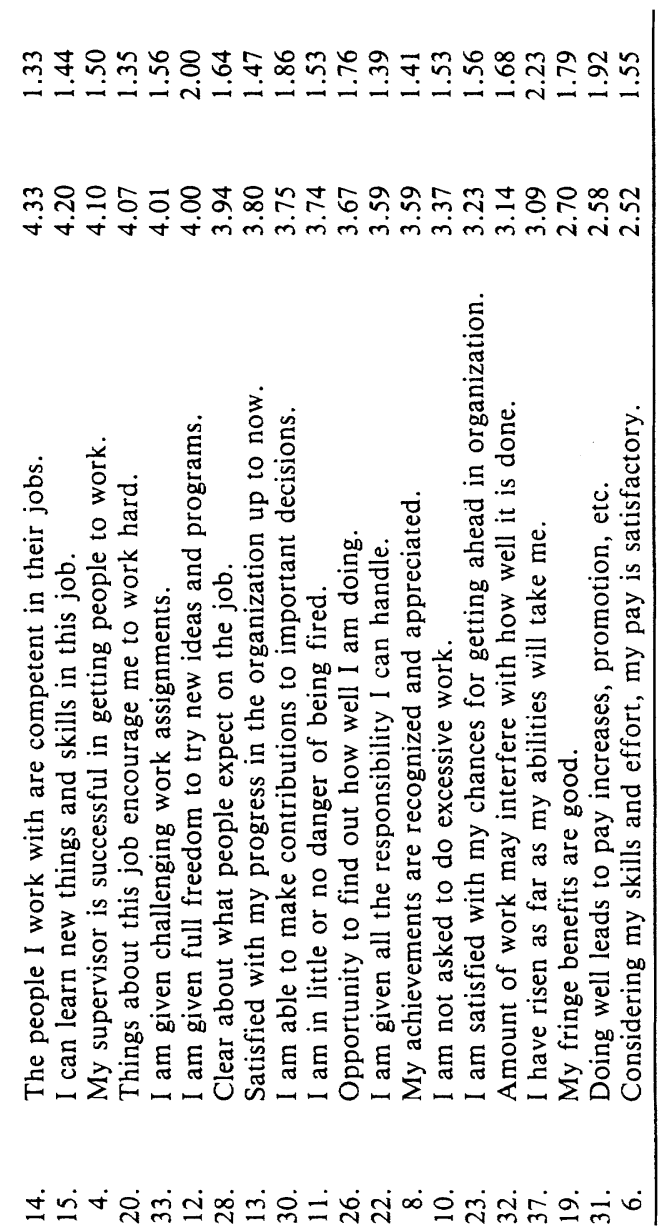


The statements to which our respondents reacted most negatively involved pay, benefits, and the opportunity for advancement. In ascending order, these items were as follows: Item 6, "Considering my skills and effort, my pay is satisfactory"; Item 31, "Doing well leads to pay increases, promotion, etc."; Item 9, "My fringe benefits are good"; and Item 37, "I have risen as far as my abilities will take me."

Taken in the aggregate, the statements with which our respondents strongly agree and disagree reflect intrinsically gratifying work and perceived inadequacies of the pay system in the district. The starting salary for a teacher in the district at the time of the study was $\$ 13,300$ and the average for all district teachers was $\$ 17,000$. Comparable figures for the entire state at the time of the study were an average starting salary of $\$ 14,019$ and $\$ 19,490$ for all teachers in the state. Thus, the perceived inadequacies of teacher pay could be interpreted as dissatisfaction with pay comparability with professional peers as well as teacher salaries vis-à-vis the market place generally. The fact is that the starting salary for a college trained teacher is well below the industrial average of $\$ 16,708$ for all classes of workers. As our analysis will reveal, moreover, dissatisfaction in the district is not a within the profession phenomenon.

Of course, the interrelationships of the various components of job satisfaction is a good deal more complex for teachers than a simple bipolar satisfaction in which intrinsic work factors are coupled with unhappiness over rewards. In order to tap these complexities the data were submitted to an $R$ factor analysis. The discussion now turns to a report of that analysis.

Analysis. The data were coded into standard numeric format, then $R$ factor analyzed using the "Factor Program" of the Statistical Packages for Social Sciences (Nie, 1975). The Varimax method of rotation was selected in order to explain the maximum possible variance. The initial run yielded an eight-factor matrix which proved unwieldy. Subsequent runs were made using the factor-limiting options of the program. The best solution considering relative percent of variance explained and conceptual clarity was the six-factor solution. Table II presents the statistical results of this solution.

The factors reported in Table II represent six attitudinal patterns. In order to understand the thought processes underlying the patterns, it was necessary to examine the factor score associations of the respondents with each factor. Once we had determined which respondents most agreed with the attitudes expressed in each factor, it became possible to examine their sorting criteria by reading the explanatory essays in the original questionnaire.

Factor I, which accounted for $22.6 \%$ of the variance, was related to collegial support and professional respect and competence. The statements 
associated with the factor all dealt with interpersonal relationships within a professional setting. Competence, trust, respect, and helpful support were the key attitudes expressed by this factor. The statement associated with the factor were:

7. The people I work with are friendly (.67).

14. The people I work with are competent in doing their jobs (.44).

16. The people I work with take a personal interest in me (.60).

24. The people I work with are helpful to me in getting my job done (.55).

27. I have confidence and trust in the persons in my work group (.53).

29. I get respect from other employees (.41).

There were no strongly negative variables associated with this factor.

An analysis which was limited to an interpretation of factor loadings might give considerable weight to the interrelationship of these social/professional variables based upon the amount of variance explained by the factor $(22.6 \%)$. As noted in the protocol, however, our respondents were asked to amplify their sorting decisions in brief essays regarding their extreme statements. The respondents, therefore, were grouped according to the factor that evoked their most extreme factor scores. When the essays of persons strongly associated with Factor I were examined, a different picture emerged.

Among the respondents whose factor scores were strongly associated with Factor I, none had a positive association. In other words, persons associated with the factor are distinguished by their rejection of its positive social/professional variables.

The most negative response to the factor was that of respondent 79 with a factor score of -2.74 . This female teacher in her second year of teaching explained:

No help was given to me unless I asked. I didn't know there were so many professionals that really weren't professionals, attitudewise.

Despite this dissatisfaction with her colleagues, the respondent expressed satisfaction with the intrinsic elements of the job, writing:

I get a feeling of importance, even though my job is a small one. It's great to hear a student tell you she or he enjoyed what they did in class or say, "I didn't know that or I'll remember that."

Respondent 18 expressed similar sentiments. This female teacher with 5 years of experience had a negative factor score of -2.57 . Her concerns were with a lack of guidance: "How can I know how well I'm doing if I don't know what to do?" She also expressed a discontent with pay and benefits stating: "Benefits are proof of a job well done." On the positive end, 


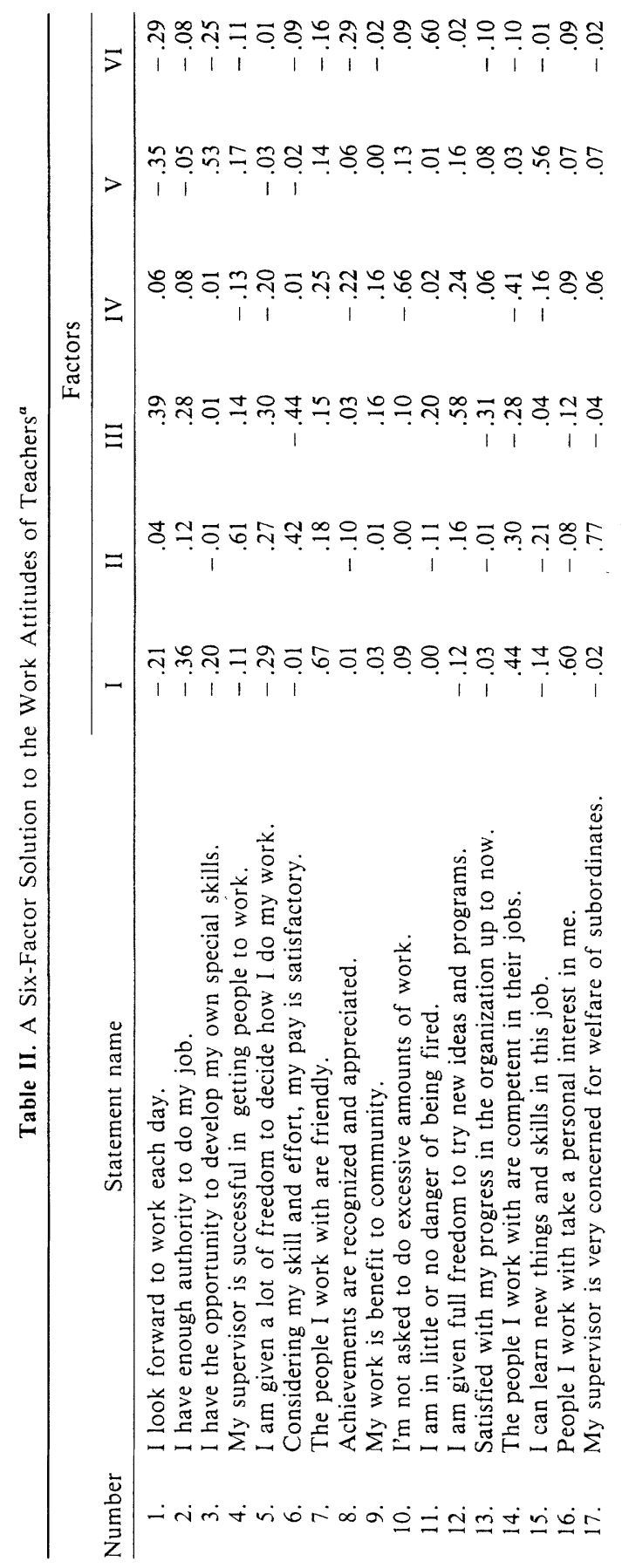




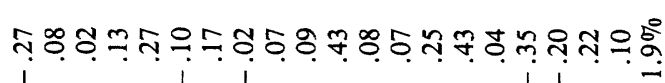

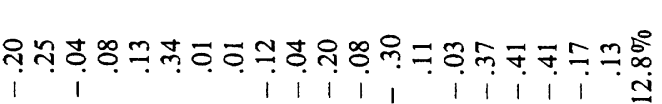
mำ

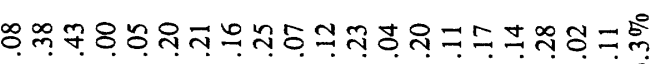
$i i_{i} i_{i} i$

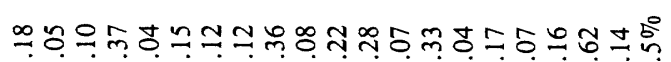
i i i i i i i i i i i i

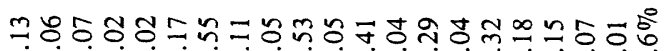
i i i i i i i i i i

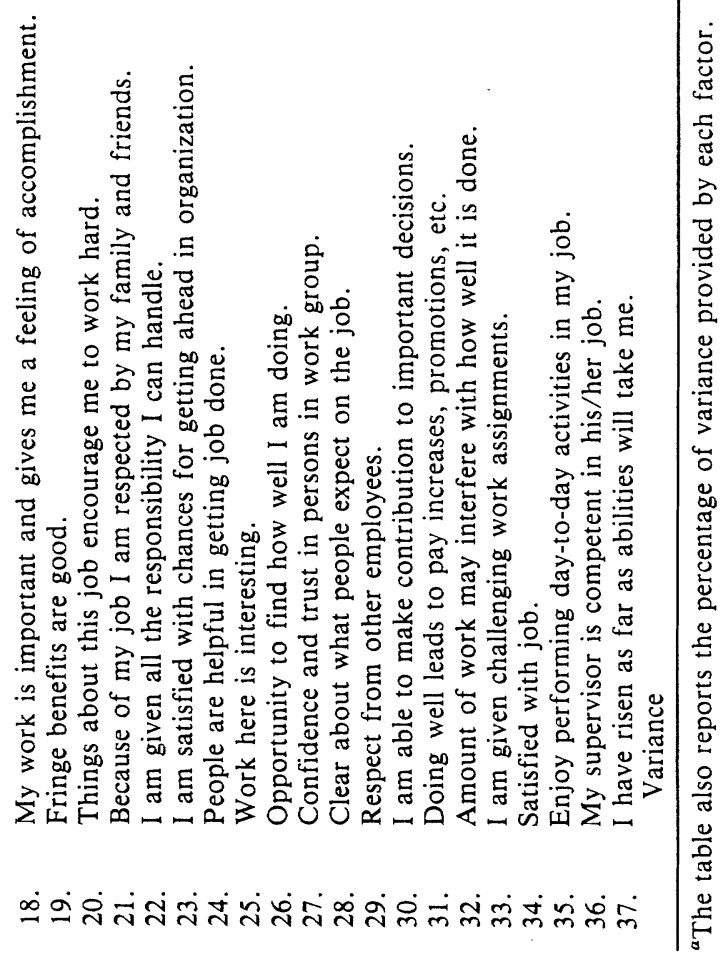


however, she writes:

My work is important and gives me a feeling of accomplishment because it is a benefit to the community. My supervisor makes work easier by being concerned.

Thus, this person is positive toward her supervisor and her work and negative toward the overall help and support she receives.

The bulk of the comments registered by persons associated with Factor I were in the same vein, dealing with concerns about their colleagues' competence to meet the challenge of their profession. They also were concerned about the lack of collegial support.

Factor II, the positive supervisor negative feedback factor, accounted for $21.5 \%$ of the variance. The variables associated with this factor were:

17. My supervisor is very concerned about the welfare of those under him/her (.77).

36. My supervisor is competent in doing his/her job (.62).

4. My supervisor is successful in getting people to work together (.61).

26. My job gives me the opportunity to find out how well I am doing $(-.36)$.

The most extreme factor score association (2.64) with this factor was that of respondent 85 who did not report her years of teaching experience. She wrote:

It is of importance to me to have my supervisor concerned for all. It would not be possible to work with others that are unfriendly or unconcerned.

The second most extreme association (factor score 2.54) was respondent 17, a 15-year teacher, who mixed autonomy with her positive assessment of her supervisor. She wrote: "My supervisor is competent and I have leeway in doing my work." Respondent 74 , a female teacher with 7 years experience and a factor score of 2.54 expressed satisfaction with her job and an impatience with co-workers, apparently, other than her supervisor. She wrote: "I'm satisfied with my job, the freedom I have to do my work - and it gives me a feeling of accomplishment." On the other hand, she wrote: "The people I work with are not as helpful as I would like."

The general positive expressions of these respondents regarding their supervisors goes against the single negative variable associated with the factor which dealt with the opportunity to find out how well one is doing. Perhaps supervisors in this organization are not perceived as responsible for giving employees feedback. More likely, however, is the possiblity that the supervisors are viewed positively despite the fact that they do not provide systematic feedback to teachers.

Factor III accounted for $16.3 \%$ of the variance and dealt positively with intrinsic work variables and negatively with extrinsic elements such as 
pay and district policies. The variables associated with the factor were:

12. I am given full freedom to try out new ideas and programs (.58).

1. I look forward to coming to work each day (.39).

6. Considering my skills and the effort I put into the work, I am satisfied with my pay $(-.44)$.

20. There are things about working here (people, policies, or conditions) that encourage me to work hard $(-.43)$.

The two persons strongly associated with this factor were respondent 65 , a female elementary teacher with 23 years experience (factor score 1.85) and respondent 91 , a female elementary teacher with 7 years experience (factor score 1.43). Both respondents expressed overall satisfaction with intrinsic work elements and indifference or dissatisfaction with pay matters. Respondent 65 wrote:

I look forward to coming to work each day because I enjoy the freedom of developing and teaching new ideas/skills for a new program. By this I can learn new things which is motivating to me.

On the negative side she wrote:

I feel I could be given more responsibility to fulfill better my capabilities - therefore I don't feel overworked and am not concerned with pay, bonuses, with the amount of work assigned.

Respondent 91 also was generally satisfied. She wrote:

I feel a sense of accomplishment about my work and its benefit to the community. My job is a position that is respected by others; therefore, I feel good about myself and $m y$ job (italics in the original).

Pay and benefits for respondent 91 were a matter of discontent rather than indifference as expressed by respondent 65 . Respondent 91 wrote:

I feel that much of the time my work is not recognized and that for the time and effort I put into my job I can't really look forward to raises or bonuses of any consequence. However, I feel good about my job and do not really expect extravagant pay or raises. I dwell on the positive aspects of my job.

Factor IV, the work factor, accounted for $14.8 \%$ of the variance. The variables associated with the factor were:

22. I am given all the responsibility I can handle (.55).

25. My work here is interesting (.51).

18. My work is important and gives me a feeling of accomplishment (.37).

10. I am not asked to do excessive work (.66).

There were two respondents strongly associated with this factor, one positive and one negative. The extreme positive person was respondent 2 , a female elementary teacher with 23 years experience and a factor score of 1.70. She wrote: "The people I work with give me respect, are friendly and I 
have confidence and trust in them." On the negative end she wrote: "I feel I am asked to do excessive work without reward. Therefore, I am not enjoying my work."

Respondent 74 is an elementary teacher with 7 years experience. Her factor score association was -2.18 . Like respondent 2 , respondent 74 expressed positive feelings about her co-workers: "My fellow teachers are friendly and helpful." However, she feels that her skills are not fully utilized. She writes: "My job is becoming less of a challenge each year."

The contrasts of the two perceptions typifies the attitudes expressed in the factor. Interestingly, respondent 24 indicated that he had extra responsibilities while respondent 2 did not.

Factor V, the positive development negative task, negative overall satisfaction factor, accounted for $12.8 \%$ of the variance. The variables associated with the factor were:

15. This is a job where I can learn new things, learn new skills (.56).

3. I have an opportunity to develop my own special abilities (.53).

23. I am satisfied with my chances of getting ahead in this organization in the future (.34).

34. I am satisfied with my job. (-.41).

35. I enjoy performing the actual day-to-day activities that make up my job $(-.41)$.

The contents of Factor $\mathrm{V}$ illustrate the complexity of worker motivation and satisfaction. On the one hand, we see a positive association of the opportunity for self-development and the potential for advancement. On the other, we see a negative reaction to the content of the work and a general dissatisfaction with their jobs. Apparently, it is possible for persons to have burned out on the specific content of their jobs and still maintain an objective perspective on the positive aspects of their profession.

Some insights into the nature of this paradox can be gained from their explanatory essays. Respondent 14 , a male secondary teacher with 13 years experience, had a factor score of 2.31 and wrote:

The positive attributes of the job are alike because of my interest in my subject area.

Many other jobs are too precise and don't allow for personal interests.

Respondent 38, a female with 10 years experience, also was strongly associated with the factor (2.17) and expressed a generally positive attitude about her job:

I need to feel accomplishment. I like the respect I receive as well as being able to learn new things and skills to better accomplish my goal.

Neither of these positive statements square with the dissatisfaction over the contents of the work or a general dissatisfaction. Both 
respondents, however, wrote strong negative statements regarding the causes for their dissatisfaction. Respondent 14 expressed a dissatisfaction with pay and with the treament of teachers. He wrote:

The negative attributes of this job are related to the fact that teachers aren't really treated like professionals. Salary (a real opinion of worth) isn't comparable to the amount of preparatory work and actual work associated with the job (italics in the original).

For respondent 38 , dissatisfaction was a matter of work overload:

Challenging work at this time is more like unpleasant work assignments because I am being asked to perform more work than is usually required in my area. I am not sure I look forward to coming to work each day.

Perhaps what the factor expresses is a general sense of satisfaction that is being eroded by excessive work and inadequate pay.

Factor VI, the positive security, clear expectations, and negative work level factor accounted for $11.9 \%$ of the variance. The variables associated with the factor were:

11. In this job I am in little or no danger of being fired (.60).

28. I am clear about what people expect me to do on the job (.43).

32. The amount of work I have to do may interfere with how well it gets done (.43).

Respondent 52's factor score of 1.48 was the most positively associated with the factor. She wrote: "I feel I have a good attitude because of the respect I have from friends and family." On the negative side she wrote:

I feel I have not gone to the limits of my abilities. I would feel better about my job and coming daily if my services were more appreciated and the pay better.

The strongest negative association with the factor was that of respondent 49 , factor score of -2.34 , who wrote: "I feel I am very competent and qualified to do my job which is of the utmost importance to the cultural development of the community." His explanation of his negative responses mirrors the content of the factor. He wrote: "I feel I have little room for advancement but am in danger of constantly being fired due to public opinion."

All the respondents associated with Factor VI expressed an intrinsic worth to their work and a sense of personal satisfaction from their jobs. At the same time, some were pessimistic about the school administration's and the public's opinion of their work. They wished they could get some feedback in terms of appreciation or pay. No respondent expressed satisfaction with job security which was the variable most associated with the factor. 


\section{DISCUSSION}

The research used a forced choice distribution and factor analysis to address the following questions:

To what degree are teachers satisfied/dissatisfied with current pay levels? And how important is pay relative to other factors such as work autonomy, intrinsic work elements, responsibility levels, and the satisfaction of so-called higher-order needs.

The analysis yielded a six-factor matrix which was more complex than what might have been achieved utilizing a simpler survey research approach. Each factor expressed a configuration of positive and/or negative attitudes which clearly differentiated it from the other factors in the matrix. Factor I dealt with social variables and collegial support. Factor II expressed a generally positive attitude toward the supervisors of the respondents. Factor III clearly expressed gratification from intrinsic work elements and dissatisfaction with extrinsic elements such as pay and benefits. Factor IV was a mixture of attitudes regarding work loads and positive expressions of gratification from important, interesting work and appropriate levels of responsibility. Factor $\mathrm{V}$ also was a mixture involving satisfaction with opportunities for learning and self-development and negative overall satisfaction from the day-to-day duties of the position. Factor VI involved job security, clear expectations, and excessive workloads.

The factor analysis was supplemented with a review of the explanatory essays written by the respondents with the strongest associations to the various factors. Analysis of these essays revealed a commonality of attitudes among respondents that was not evident in the factor matrix. These essays consistently revealed a sense of pride and accomplishment related to the intrinsic factors of the teaching profession.

The negative references in the essays expressed dissatisfaction with collegial support, feedback regarding performance, a general dissatisfaction with rewards, and a sense that the public does not recognize and appreciate the contributions of teachers.

Pay Perceptions. Among our respondents, there was a general dissatisfaction with pay and other benefits. Rewards, however, did not constitute the principal element in any factor. Pay was negatively associated only with Factor III (pay - .44; benefits - .38). Even here, pay was subsumed by a higher positive association (.58) of the autonomy need. Nor do our findings lend support to the cause of merit pay for teachers. Pay dissatisfaction among teachers in this district is framed as pay for teachers as a profession rather than differential rewards for individual performances. Only one respondent gave an indication that she might favor merit pay by expressing a desire for bonuses in her essay. It is not clear, however, that she would prefer individual rather than district-wide bonuses. 
Based upon our data we can anticipate negative consequences from merit pay. In order to implement merit pay, organizations must standardize their evaluation criteria. For such criteria to be valid, how jobs are performed also must be standardized. Thus, the autonomy and control of their workday which teachers find so gratifying (and presumably motivating) would be sacrificed in the interest of implementing a mode of compensation.

The cause of recruiting and retaining quality teachers would be best served by generally upgrading teachers' pay and the installation of organization support systems to assist new and/or struggling teachers. Our respondents, for example, lamented the absence of collegial support and feedback from the administration regarding their performances. Collegial support could be enhanced by the adoption of quality circles (Ouchi, 1981) in which teachers could discuss their problems and frustrations as well as share successful teaching techniques with their peers. The problem of performance feedback could be addressed through a supervisory counseling system in which principals would regularly meet with individual teachers to counsel them about their performance and make constructive suggestions on how to improve performances where necessary.

Implications. Teacher motivation in this study is composed of the freedom to try new ideas, appropriate responsibility expectations and intrinsic work elements. These elements are of transcendent importance to our respondents. The most important finding in this regard is that the respondents expressed gratification rather than frustration of these work needs. Given the foregoing, motivation schemes such as merit pay may prove counterproductive in organizations which employ professionally trained individuals to provide services rather than produce a product.

\section{REFERENCES}

BROWN, S. R. Political subjectivity. New Haven: Yale University Press, 1980.

CAMPBELL, J. P., \& PRITCHARD, R. Motivation theory in industrial psychology, In M. Dunnette (Ed.), Handbook of Industrial and Organizational Psychology. Chicago: Rand McNally, 1976, pp. 63-130.

GEORGOPOULOUS, B. S., et al. A path-goal approach to productivity. Journal of Applied Psychology, 1957, 4l(1), 345-353.

HERZBERG, F. Work and the nature of man. Cleveland: World Publishing Co., 1966.

MASLOW, A. Motivation and personality. New York: Harpers, 1954.

NIE, N. H., et al. Statistical package for the social sciences. New York: McGraw-Hill, 1975.

OUCHI, W. A. Theory Z. Reading: Addison Wesley Publishing Co., 1981.

PORTER, L., \& LAWLER, E. Managerial attitudes and performances. Homewood. Illinois: Irwin-Dorsey Press, 1968.

STEPHENSON, W. The study of behavior: $Q$ technique and its methodology. Chicago: University of Chicago Press, 1953.

VROOM, V. Work and motivation. New York: John Wiley and Sons, 1964. 


\section{BIOGRAPHICAL NOTES}

RONALD SYLVIA is an Associate Professor of Political Science at The University of Oklahoma. He received his BA from California State College at San Bernardino and his MPA and $\mathrm{PhD}$ from Kent State University. He has taught at several universities and as a consultant to federal, state, and local government. He has published articles in the fields of organization theory, behavior psychology, personnel management, as well as political science.

ANTHONY M. HUTCHISON received his bachelor's degree with honors in history from the University of Oklahoma where he also earned his master's in public administration. He is currently employed by the Legislative Reference Service of the Oklahoma State House of Representatives. 